\title{
Working with traditional healers in Harare
}

\author{
Vikram Patel
}

As an expatriate psychiatrist, working in a new culture has exposed me to the difficulties in practising my profession, and in particular, its limitations. In search of understanding common psychosocial distress in the communities we serve, I have sought to work with traditional healers in the high-density suburbs of Harare city.

Traditional healers (TH) in Zimbabwe are grouped into two categories; the n'angas include spirit mediums and herbalists; and the faith-healers, who belong to one of the many African Christian churches which flourish in the country and use methods which syncretise traditional treatments with Christian beliefs. The most obvious role of these different TH as depicted in much of the cross-cultural literature is that of the 'native medicine-man' in which health is defined along Western concepts of disease entities. In addition to health care, TH are also religious consultants, legal advisers, social workers, marriage counsellors, and family therapists (Staugard, 1985). TH are relatively well organised; shortly after independence in 1980, the Zimbabwe National Association of Traditional Healers (ZINATHA) was formed by amalgamating eight other small organisations, with aims not dissimilar to professional bodies of biomedical healers. The significance of $\mathrm{TH}$ in the political and cultural structure of society is demonstrated by the fact that spirit mediums are historically recognised to have been guiding lights in the war of independence (Lan, 1985) ZINATHA was formed with the active encouragement of eminent liberation leaders and is currently headed by Professor Chavunduka who is also the Vice-Chancellor of the University of Zimbabwe. While ZINATHA plays an important role in registering healers and publishing registers and occasional papers, its role in research and training is limited due to a number of reasons including financial constraints and political problems. The latter saw a new organisation representing healers form in 1991 (Zimbabwe Traditional Healers Association - ZITHA), headed by the then Minister of Health.

My work with healers has seen active cooperation by both the major organisations mentioned. Their enthusiasm and lack of bureaucracy has been refreshing. Undoubtedly it has been the open welcome by individual healers to allow our research team to sit in their homes and interview them and their patients which has convinced us that healers have nothing to hide. Their openness to improving their practice is supported by the findings of a recent survey of 97 healers in two suburbs; virtually all came out in strong support of collaboration with biomedical services. The intimate knowledge healers have of their patients' psychosocial problems has enlightened me in my clinical work. For example, I am less likely to consider a complaint of being bewitched as a bizarre idea and more sympathetic that this may be a way of making a difficult emotional experience meaningful to the sufferer.

The combination of widespread use of healers and the problems with health manpower highlights the need for innovative experiments in making healers co-partners in primary health care. There is resistance to such a move from two influential sectors of society. First, there is a wide gulf between orthodox Christian and traditional religion and the former is one of the principal sponsors of biomedical health care in the country. At one meeting, a traditional healer accused all black missionaries who denied the importance of traditional beliefs in ancestral spirits as still being 'colonised', raising the temperature of a senior official from a missionary hospital. It took some diplomacy to get back to the issue of that day - writing a proposal to set up a pilot collaborative venture between the different care providers! Secondly, biomedical health practitioners, not least nurses, have grave doubts about the positive 
aspects of traditional medicine. Thus, healers are accused of being backward, unscientific or static, although studies show that they can adapt to changing knowledge about medicine, for example, increasingly recognising that some illnesses respond better to biomedicine and referring such patients accordingly.

Many healers are accused of being charlatans, a suspicion confirmed by some healers themselves, although there is no evidence to suggest that there are any more charlatans than in medicine or any other professional group. The observation that many patients attending biomedical facilities are either treatment failures or suffering from toxic side-effects of traditional medicine fails to evaluate those who are successes of traditional medicine and thus do not attend biomedical health care, nor does it consider the substantial problems of iatrogenic illness and side-effects caused by biomedical treatments. It is felt that the two types of health professionals will not be able to work together. However, recent work suggests that although there is initial mistrust, collaboration is not only possible, but effective (Hoff \& Nhlavana Maseko, 1986). In a pilot study in Zimbabwe involving cooperation between traditional and biomedical healers, patients reported that they were very satisfied with being able to consult both, and asked why this was not more widely available (Stott et al, 1988). Finally, it is often stated that there is no evidence for the efficacy of traditional medicine. However, what research has been done shows that it is of benefit to substantial groups of patients, especially those with psychosocial problems (Lamont, 1988).

Balancing this enthusiasm for working with healers, one must be aware of the problems in their practices. Unhygienic methods such as scarifications cause concern to many, especially with the current risks of HIV disease.

As biomedical healers, we need to maintain an openness towards the role of our colleagues in the traditional sector. However different our backgrounds and belief systems may be, we need to recognise our common goal of relieving psychosocial distress. At the same time, we must be careful not to romanticise traditional medicine as a panacea for all problems. Only by establishing a constructive dialogue and by researching and evaluating different therapeutic approaches can doubts and suspicions be cleared. In the difficult circumstances that prevail in countries like Zimbabwe, understanding the cultural reality of health care represents a promising avenue to reducing the disability of common mental disorders.

\section{Acknowledgements}

I wish to acknowledge the Beit Medical Trust, German Technical Cooperation (GTZ) and the Zimbabwe Ministry of Health for their support to my research; and thank Mark Winston for his comments.

\section{References}

HoFf, W. \& Nhlavana Maseko, D. (1986) Nurses and traditional healers join hands. World Health Forum. 7. 412-416.

LAMONT, A. M. (1988) Severe invalidism-the dominant feature of Third-World psychiatry in southern Africa. South African Medical Journal, 73, 430-433.

LAN, D. (1985) Guns \& Rain: guerillas and spirit mediums in Zimabawe, London: James Currey.

STAUGARD, F. (1985) Traditional Medicine in Botswana traditional healers. Gaborone: Ipelegeng Publishers.

STOTT, R., MOOMBE, C. S., MELER, F., NYADZEMA, N. \& ZHANGU, C. S. (1988) Is cooperation between traditional and western healers possible? A pilot study from Zimbabwe. Complementary Medical Research, 3, 15-22.

Vikram Patel, Visiting Lecturer, Department of Psychiatry, Medical School, University of Zimbabwe and Beit Research Fellow, Section of Epidemiology \& General Practice, Institute of Psychiatry, London

Correspondence: $\mathrm{Dr}$ V. Patel, Department of Psychiatry, Medical School, PO Bax A178, Avondale, Harare, Zimbabwe 